\title{
EXPERIMENTAL ASSESSMENT OF COMPARATIVE R290VS. R449A REFRIGERANTS BY USING 3E (ENERGY, EXERGY AND ENVIRONMENT) ANALYSIS: A SUPERMARKET APPLICATION
}

\author{
Erhan Arslan ${ }^{1,}$, , Meltem Kosan ${ }^{1}$, Mustafa Aktas ${ }^{1}$, Suleyman Erten ${ }^{2}$
}

\begin{abstract}
Efficiency is becoming an increasingly important issue in cooling systems. It is important to use micro channel heat exchangers in order to increase the cooling system efficiency. In this study, performance analysis of refrigerants used in supermarkets was tested experimentally. Thermodynamic analyses of the refrigerants were examined. The compatibility of R290 and R449A refrigerants with the environment has been experimentally observed. Energy, exergy, and environmental analyses were performed using R290 and R449a refrigerants based on the test results for 24 hours using double inlet and double outlet evaporator. Accordingly, in the experiments using R290, the exergy efficiency and COP value are $43.52 \%$ and 2.09, respectively. In experiments using R449A, these values were found to be $22.28 \%$ and 1.59 . Exergy efficiency was increased by $48.81 \%$ in experiments using propane. In addition, an increase of $24.12 \%$ was observed in the Coefficient of Performance (COP) value. Considering the environmental analysis results, the amount of $\mathrm{CO}_{2}$ emitted by the $\mathrm{R} 290$ refrigerant to the atmosphere during the test period was $3.14 \mathrm{~kg} / \mathrm{h}$ and R449A was calculated as $3.97 \mathrm{~kg} / \mathrm{h}$. It was seen in this study that the R290 refrigerant emits $26.22 \%$ less $\mathrm{CO}_{2}$ to the atmosphere.
\end{abstract}

Keywords: Comparative R290vs. R449A, Refrigerant, Environmental Analysis, Energy and Exergy Analysis

\section{INTRODUCTION}

The most common and efficient method for cooling is air-source heat pump systems with a vapour compression refrigeration cycle. Refrigerants used in heat pump systems have environmental impacts such as ozone layer depletion and increasing the global warming. This situation has led to the publication of many international regulations such as the Kigali amendment to the Montreal Protocol [1,2] and the F-Gas Regulation [3].

Chlorofluorocarbon (CFC) and hydrochlorofluorocarbon (HCFC) refrigerants, which were used as refrigerants in cooling systems for many years, were banned by the Montreal Protocol (1987) [1] upon understanding that the refrigerants damage the ozone layer [4]. As a substitute, hydrofluorocarbon (HFC) gases developed as an alternative for the CFC and HCFC refrigerants, due to global warming effects, and the use of these gases was restricted by the Kyoto Protocol and the European Union (EU) [5].

The refrigerant with the composition of R125/R143a/R134a (44\%/52\%/4\%) is R404A which has low toxicity and is not flammable. R290 was widely used in low and medium temperature applications such as supermarkets. The use of this refrigerant has been restricted as of 2020 according to the EU Regulation No 517/2014 [5, 6]. R448A, R449A, R452A refrigerants have been used as an alternative to R404A. Makhnatch et al. [7] demonstrated that R449A can be used instead of R404A owing to its suitable thermodynamic properties and acceptable maximum discharge temperature in the supermarket refrigeration system. They confirmed that a $4 \%$ increase in refrigerant charge can provide a similar COP between R404A and R449A. Vaitkus and Dagilis [8] reported that the reduction $13 \%$ in cooling capacity and the decrease was $4 \%$ in energy consumption for R448A and R449A according to R404A. They showed that the components of R448A and R449A were very close; therefore, the performance criteria were the same.

This paper was recommended for publication in revised form by Regional Editor Hasan Köten

${ }^{1}$ Department of Energy Systems Engineering, Gazi University, Ankara, Turkey

${ }^{2}$ Nurdil Technical Cooling, Ankara, Turkey

${ }^{*}$ E-mail address: erhana1985@gmail.com

Orcid id: 0000-0001-7311-9342, 0000-0002-7540-7935, 0000-0003-1187-5120, 0000-0002-7811-6148

Manuscript Received 09 September 2020, Accepted 08 December 2020 
R290 is an inexpensive and easily available natural coolant. Additionally, R290 has zero ozone depletion potential (ODP) and low global warming potential (GWP) compared to HFCs, which are known as a short-term alternative to CFCs and HCFCs. Kyoto Protocol (1997) planned the phasing out of HFCs by 2025-2040. By 2050, HFCs are predicted to contain approximately $9-19 \%$ of projected global $\mathrm{CO} 2$ emissions. Therefore, it is urgent to popularize refrigeration technology using hydrocarbons as refrigerants such as R290. In recent years, the application of the R290 in the commercial refrigeration and air conditioners area has increased, but the refrigerant charge is limited due to safety reasons and industry regulations $[9,10]$.

Among the refrigerants examined ref. [11], R290 was found to have global warming potential (GWP) and zero emission. R290 is regarded as an environmentally friendly, economical, and practical refrigerant with suitable cooling performance $[12,13]$.

Few studies have been found for R290 in two-circuit and two-temperature cycle refrigerant systems [14-16]. R290 is a natural refrigerant with a mass and volumetric cooling capacity of $87.7 \%$ and $54.2 \%$ higher than other refrigerants (R134a), respectively [6]. In other studies, R290 was used in air conditioning and heat pump systems $[17,18]$. It was found that there was an improvement of $16.71 \%$ in the COP value in the steam compression refrigeration cycle, and it was observed that the cooling capacity increased by approximately $35 \%$ [15, 19]. Studies have proven that R290 can replace many refrigerants in domestic applications [20, 21].

Tian et al. [22] experimentally investigated the performance of the ACs operating with both R32/R290 and R410A. The experimental results indicated that the refrigerant charge amount of R32/R290 decreased by 30-35\%. The cooling and heating capacities increased by 14-23.7\%. For further decrease in the charge amount and flammability, a micro-channel heat exchanger (condenser) was employed to replace the finned tube one. Compared with R32/R290 system using the finned tube heat exchanger, the charge amount and power consumption of R32/R290 decreased by 34.1 and $0.4 \%$, respectively; the cooling capacity and the COP increased by $6.4 \%$ and $6.8 \%$, respectively.

When the literature is examined, it is seen that microchannel heat exchangers have many advantages. Microchannel heat exchangers have high heat transfer coefficients. They are lightweight due to their small size. Another advantage of its dimensions is that it can work with less amount of working fluid. Because of these advantages, microchannel heat exchangers are preferred as condensers and evaporators in cooling systems [23]. Xu et al. [24] experimentally and numerically analysed the performance of a microchannel condenser used in a domestic air conditioning system with R290 refrigerant. Results showed that the cooling capacity of the microchannel condenser system increased by $1.6 \%$, and the system refrigerant charge decreased by $28.3 \%$. Tosun et al. [25] examined the use of microchannel condenser in a household refrigerator with different amounts of refrigerant and the different sizes of capillary integration. As a result of experimental studies, the best combination of $50 \mathrm{~g}$ refrigerant and $3.25 \mathrm{~m}$ capillary for better performance was found. Cremaschi and Yatim [26] investigated the retention of oil in a microchannel condenser and evaporator of an R134a cooling system and the effect of circulating oil on heat transfer capacities and pressure drops in the microchannel heat exchangers. It was emphasized that the heat capacity of the evaporator varied between $5 \%$ and $12 \%$, and the pressure drops increased significantly.

From the given literature, it is understood that various studies have been conducted on R290 and R449A, and microchannel condenser. The aim of this study is to design a novel, efficient, and eco-friendly cooling system especially for use in supermarkets. For this purpose, a cooling system consisting of a single evaporator with 4 inlets and 4 outlets and two microchannel condensers has been designed. This cooling system was experimentally tested with both R290 and R449A refrigerant. The variation of package temperatures in the cooling of this system was investigated, too. The experiments were carried out in the test room under at the $25{ }^{\circ} \mathrm{C}$ and $60 \%$ relative humidity. In the designed cooling system, $3 \mathrm{E}$ analysis for both refrigerants were made, their performances were evaluated, and the results were compared with each other. The structure of this study is summarized in Figure 1. 


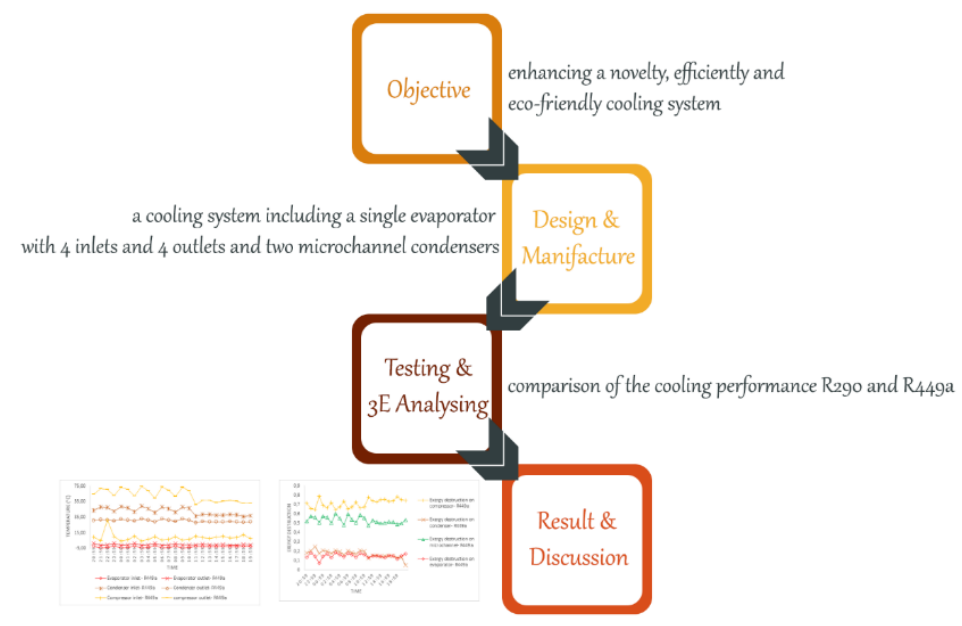

Figure 1. Structure of this study

\section{MATERIALS AND METHODS}

\section{System Description}

The schematic view of the designed cooling system is shown in Figure 2. This system mainly consists of a single evaporator, two microchannel condensers, two compressors, two capillary tubes, and other elements. This cooling system, which has a single evaporator, has two cooling cycles operating parallel to each other. The evaporator is designed so that the refrigerant coming from both cycles enters the evaporator through two inlets and exits the two outlets. The reason for this is to increase the cooling capacity by providing a homogeneous cooling in the evaporator. The dimension of the evaporator in the cooling system is $1.565 \times 0.493 \times 0.105 \mathrm{~m}$, and the condenser dimension is $0.500 \times 0.241 \times 0.070 \mathrm{~m}$. Thus, the size of the cooling system is $1.875 \times 2 \times 0.880 \mathrm{~m}$. In addition, superheat was applied at $8 \mathrm{~K}$ temperature to prevent liquid refrigerant from entering the compressor.

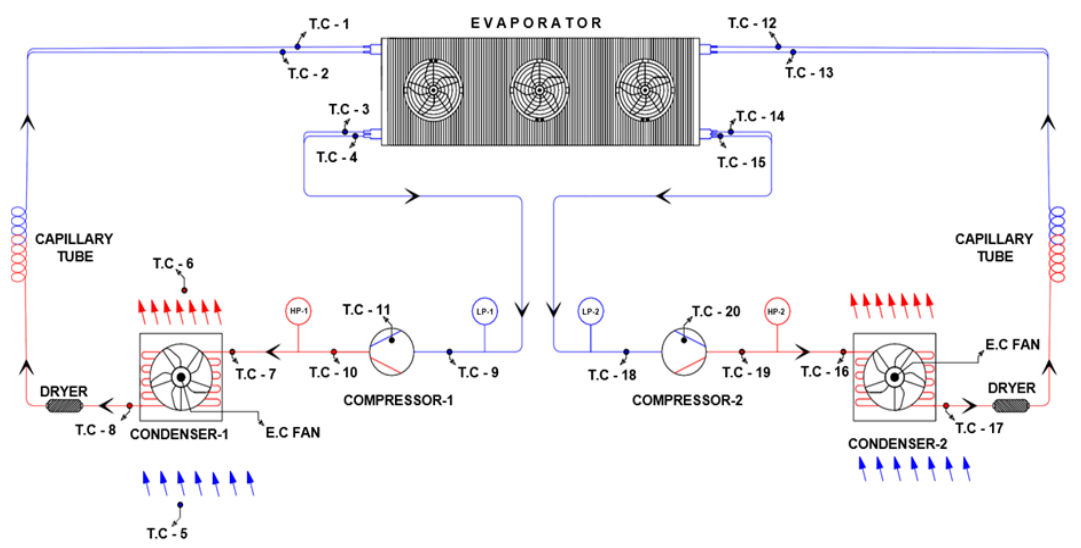

Figure 2. The schematic view of the designed cooling system

The experiments were carried out in Nurdil Cooling Company's test room with calibrated test devices within the scope of TS EN ISO 23953-2 standard. The photographs of the experimental setup are shown in detail in Figure 3. In this system, energy consumption, temperature measurements, pressure measurements were performed throughout 24 hours. Temperature measurements were taken every minute by means of thermocouples from certain points of cooling systems equipment (compressor, condenser and evaporator inlet-outlet temperature values, cooled packing temperature). 
Experimental setup and technical detail of the equipment is given Figure 3. Refrigerator where the temperature of the products is tested shown (Figure 3a). Dimenson of the Test room (Figure $3 b$ and Figure 3c) is measured as $1.88 \times 2 \times 0.88 \mathrm{~m}$. Last figure is show the Compressors of the experimental setup (Figure 3d).

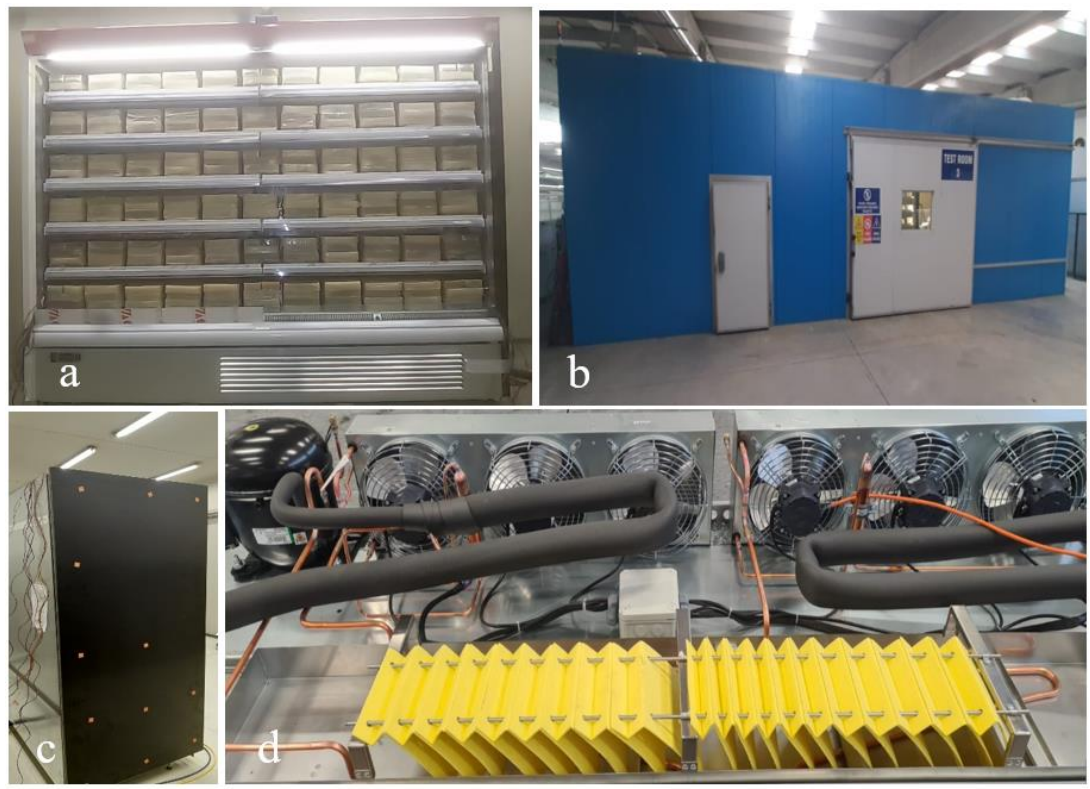

Figure 3. Photographs of the experimental setup

Some parameters were measured with energy analyzers in the test rooms. Parameters such as the energy consumption values of the system, pressure transmitters, low-high pressure values and the flow rate of the refrigerant are among these measured values. Information on measurement equipment used in experiments and tests are given in Table 1.

Table 1. Measuring instruments used in experiments

\begin{tabular}{|l|c|c|c|c|}
\hline \multicolumn{1}{|c|}{ Device } & Model & Measuring Range & Unit & Accuracy \\
& & & & \\
\hline Thermocouple & Omega, CL-23A & $-40 /+150{ }^{\circ} \mathrm{C}$ & ${ }^{\circ} \mathrm{C}$ & $\pm \% 0.02$ \\
\hline Pressure transmitter & Eliwell, HP & $0-30 \mathrm{bar}$ & $\mathrm{bar}$ & $\pm 0.1 \mathrm{bar}$ \\
\hline Pressure transmitter & Eliwell, LP & $0.5-8 \mathrm{bar}$ & $\mathrm{bar}$ & $\pm 0.01 \mathrm{bar}$ \\
\hline Thermohygrometer & Rotronic, M23W2HT-1X & $0 /+50{ }^{\circ} \mathrm{C}$ & ${ }^{\circ} \mathrm{C} / \% \mathrm{RH}$ & $\pm \% 1.5 \mathrm{RH}$ \\
& & $0-100 \% \mathrm{RH}$ & & $\pm 0.03{ }^{\circ} \mathrm{C}$ \\
\hline Anemometer & E+E Electronic, EE66-VA3 & $0-2 \mathrm{~m} / \mathrm{s}$ & $\mathrm{m} / \mathrm{s}$ & \pm 0.01 \\
& EE660-V7 & $0.04-0.8 \mathrm{~Pa}$ & $\mathrm{~Pa}$ & \pm 0.02 \\
\hline Vacuum pump & Value, VP2200 & $0-100 \mathrm{~kg}$ & $\mathrm{~g}$ & $\pm \% 0.05$ \\
\hline Digital scales & Value, VES-100B & $-50 /+150{ }^{\circ} \mathrm{C}$ & $\mathrm{bar}$ & $\pm 0.1{ }^{\circ} \mathrm{C}$ \\
\hline Digital manifold & Testo, 550 & $-1 /+60 \mathrm{bar}$ & & $\pm 0.01 \mathrm{bar}$ \\
\hline Energy analyzer & Janitza, UMG508 & & $\mathrm{Ampere}$ & $\begin{array}{c}\text { Current } \\
\pm \% 0.2\end{array}$ \\
& & & Volt & $\begin{array}{c}\text { Voltage } \\
\pm \% 0.1\end{array}$ \\
\hline Flowmeter & Siemens, SITRANS FC MASS & $0-1000 \mathrm{~kg} / \mathrm{h}$ & $\mathrm{kg} / \mathrm{h}$ & $\pm \% 0.1$ \\
\hline
\end{tabular}




\section{Energy and Exergy Analysis}

To specify the exergy losses or destructions in the system, thermodynamic analysis is made. In this study, the following assumptions are made:

1. Steady state conditions remain in all the components.

2. Pressure losses in the pipelines are neglected.

3. Heat gains and heat losses from the system or to the system are not considered.

4. Kinetic and potential energy and exergy losses are not considered [27-29].

Details of the acceptance analysis for experiments is given in Table 2. It can be seen from Table 1 that the superheating and supercooling temperature are $8 \mathrm{~K}$ and $5 \mathrm{~K}$, respectively.

Table 2. Acceptance details for the analysis

\begin{tabular}{|l|l|l|}
\hline Parameter & (unit) & Value \\
\hline Evaporation temperature & $(\mathrm{K})$ & 263 \\
\hline Condensation temperature & $(\mathrm{K})$ & 318 \\
\hline Superheating & $(\mathrm{K})$ & 8 \\
\hline Supercooling & $(\mathrm{K})$ & 5 \\
\hline Isentropic efficiency & $(\%)$ & 83 \\
\hline
\end{tabular}

The amount of heat transferred from evaporator is given Eq. (1) [27-29]:

$$
\dot{Q}_{e v a}=\dot{m}\left(h_{1}-h_{4}\right)
$$

The amount of heat transferred from condenser is given as Eq. (2):

$$
\dot{Q}_{\text {con }}=\dot{m}\left(h_{2}-h_{3}\right)
$$

The compressor capacity and the electrical power of the compressor can be calculated using Eq. (3).

$$
\dot{W}_{\text {comp }}=\dot{m}\left(h_{2}-h_{1}\right)
$$

The coefficient of performance (COP) corresponding to the energy consumed by the compressor per unit time and the heat transferred from the evaporator per unit time is given in the Eq. (4):

$$
C O P=\frac{\dot{Q}_{e v a}}{\dot{W}_{c o m p}}
$$

Exergy flow for each point is given Eq. (5):

$$
\dot{E}_{x}=\dot{m}\left[h-h_{0}-T_{0}\left(s-s_{0}\right)\right]
$$

Exergy destruction on compressor is calculated by Eq. (6):

$$
\dot{E}_{x, \text { dest }, \text { comp }}=\dot{m}\left[\left(h_{1}-T_{0} s_{1}\right)\right]-\left[\left(h_{2}-T_{0} s_{2}\right)\right]+\dot{W}_{\text {comp }}
$$

Exergy destruction on condenser is calculated by Eq. (7): 


$$
\dot{E}_{x, \text { dest }, \text { con }}=\dot{m}\left[\left(h_{2}-T_{0} s_{2}\right)\right]-\left[\left(h_{3}-T_{0} s_{3}\right)\right]-\left[\dot{Q}_{c o n}\left(1-\frac{T_{0}}{T_{\text {con }}}\right)\right]
$$

Exergy destruction on evaporator is given by Eq. (8):

$$
\dot{E}_{x, \text { dest }, e v a}=\dot{m}\left[\left(h_{1}-T_{0} s_{1}\right)\right]-\left[\left(h_{4}-T_{0} s_{4}\right)\right]-\left[\dot{Q}_{c o n}\left(1-\frac{T_{0}}{T_{\text {eva }}}\right)\right]
$$

Microchannel exergy destruction is given by Eq. (9):

$$
\dot{E}_{x, \text { dest }, m c h}=\dot{m}\left[T_{0}\left(s_{3}-s_{4}\right)\right]
$$

Finally, total exergy destruction can be defined as Eq. (10):

$$
\sigma_{\text {total }}=\sigma_{\text {ext,p }}+\sigma_{\text {ext }, m}
$$

It is important to perform energy exergy analysis in refrigerant systems. Therefore, the exergy balance for the steady flow control volume in this study is given Eq. (11) and Eq. (12):

$$
\begin{gathered}
\eta_{\text {ex }=} \frac{\dot{E}_{x, 4}-\dot{E}_{x, 1}}{\dot{W}_{\text {comp }}} \\
\eta_{\text {ex }=} \frac{\dot{m}\left[\left(h_{1}-T_{0} s_{1}\right)\right]-\left[\left(h_{4}-T_{0} s_{4}\right)\right]}{\dot{m}\left(h_{2}-h_{1}\right)}=\frac{\left[\left(h_{1}-T_{0} s_{1}\right)\right]-\left[\left(h_{4}-T_{0} s_{4}\right)\right]}{\left(h_{2}-h_{1}\right)}
\end{gathered}
$$

\section{Environmental analysis}

In this study, an environmental analysis was carried out to investigate how environmentally friendly R290 and R449A refrigerants were. However, the compressors in the system work with electricity. In the production of this electrical energy, carbon dioxide $\left(\mathrm{CO}_{2}\right)$ emission is created depending on the fuel source of the power plant. In this part of the study, $\mathrm{CO}_{2}$ emissions will be calculated for each refrigerant based on compressor power consumption. To perform this calculation, the system's compressor (for all refrigerant applications) is assumed to be running for 24 hours. However, only the compressor power consumption is evaluated. Fan etc. It is not taken into account in the power consumption analysis of the equipment.

Environmental economy analysis is based on the $\mathrm{CO}_{2}$ emission price and the amount of carbon emitted. This analysis is valuable in obtaining a carbon price to reduce greenhouse gas emissions. The carbon price approach is a good approach for cost calculation of greenhouse gases. To prevent greenhouse gases being released into the atmosphere, having a price of $\mathrm{CO}_{2}$ emitted will result in a reduction of the carbon emitted. This will also reveal the importance of renewable energy technologies. [30]. In another study, the average $\mathrm{CO}_{2}$ equivalent density for electricity production from coal was stated as $960 \mathrm{~g} \mathrm{CO}_{2} / \mathrm{kWh}$ [31]. Indeed, this rate will be $2.08 \mathrm{~kg} \mathrm{CO} / \mathrm{kWh}$, considering $40 \%$ transmission and distribution losses and $20 \%$ losses due to insufficient electrical appliances used [32]. Therefore, $\mathrm{CO}_{2}$ reduction for refrigerant system is given in Eq. (13):

$$
\Phi_{\mathrm{CO}_{2}}=\Psi_{\mathrm{CO}_{2}} \times \dot{W}_{\mathrm{comp}}
$$

where $\Phi_{\mathrm{CO}_{2}}$ represents the amount of $\mathrm{CO}_{2}\left(\mathrm{~kg} \mathrm{CO}_{2} / \mathrm{h}\right)$ reduced per hour and $\mathrm{CO}_{2} \Psi_{C_{2}}$ indicates the average amount of $\mathrm{CO}_{2}$ emissions ( $\left.2.08 \mathrm{~kg} \mathrm{CO} / \mathrm{kWh}\right)$ generated during the production of energy from coal. 


\section{RESULTS AND DISCUSSION}

In the refrigerator system with an internal microchannel, the thermodynamic analysis of R290 and R449A refrigerants as an alternative refrigerator were analysed according to the first and second law of thermodynamics in this paper.

The temperature of the experiment using R290 as the refrigerant is given in the Figure 4 which shows the input-output temperatures of the system components. Compressor's maximum, minimum and average inlet-outlet temperatures were measured as $19.03-69.42{ }^{\circ} \mathrm{C}, 13.84-47.58^{\circ} \mathrm{C}$, and $15.94-60.42^{\circ} \mathrm{C}$, respectively. Condenser maximum, minimum and average temperature values were measured as $43.05-31.74^{\circ} \mathrm{C}, 31.80-26.06^{\circ} \mathrm{C}$, and 37.98 $29.85^{\circ} \mathrm{C}$; evaporator temperature values were measured as $-1.94-4.55^{\circ} \mathrm{C},-4.78-0.50^{\circ} \mathrm{C}$, and $-3.33-1.99^{\circ} \mathrm{C}$.

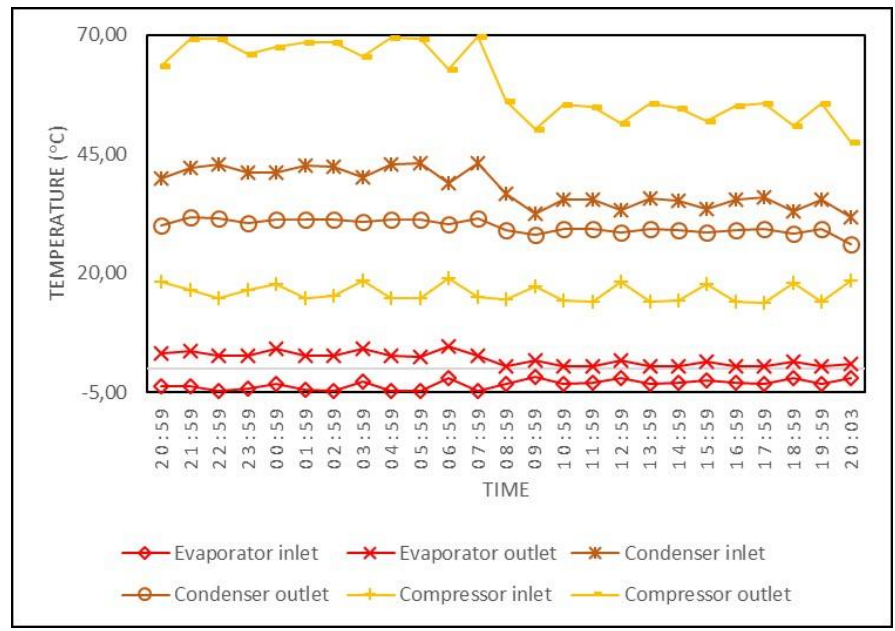

Figure 4. Temperature of the system components where R290 was used as refrigerant

The exergy destruction of the system elements according to the measurement moment is shown in Figure 5. According to Figure 5, the highest exergy destructions of the compressor, condenser, microchannel and evaporator are $0.5556 \mathrm{~W}, 0.2571 \mathrm{~W}, 0.1533 \mathrm{~W}$ and $0.3094 \mathrm{~W}$; minimum values are $0.4090 \mathrm{~W}, 0.0480 \mathrm{~W}, 0.0031$ and 0.2525 ; the average values are $0.4816 \mathrm{~W}, 0.1477 \mathrm{~W}, 0.102 \mathrm{~W}$ and $0.2930 \mathrm{~W}$ determined, respectively. It has been observed that the biggest exergy destruction in the system is in the compressor. It refers to exergy destruction irreversibilities or assessing the degraded resources and specifies the elements in the system where destruction is occurring. Thus, by improving the compressor in the R290 refrigerant cooling system, exergy destruction can be reduced and the system can operate more efficiently.

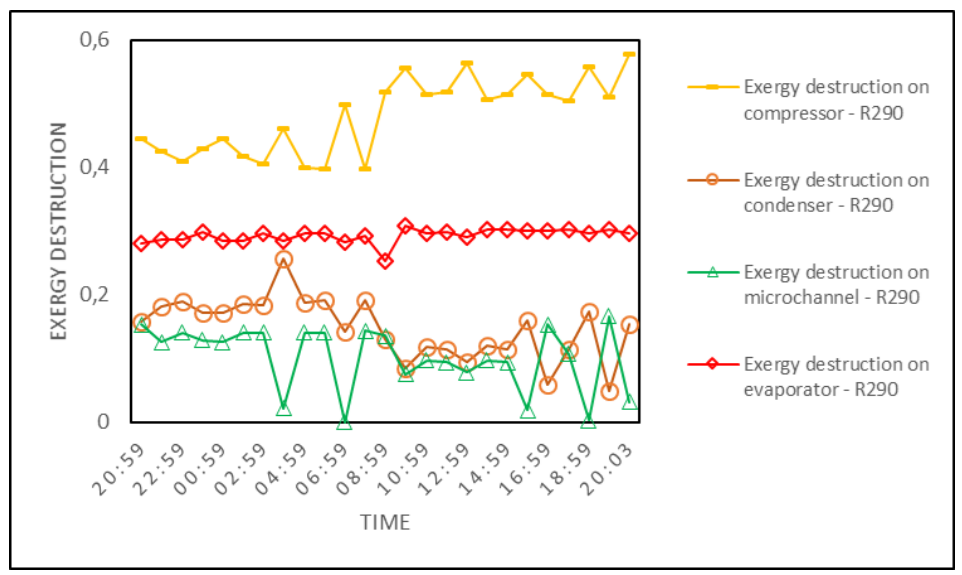

Figure 5. Exergy destruction of the system components where R290 was used as refrigerator 
The temperature of the experiment using R449A as the refrigerant is given in Figure 6 which shows the input-output temperatures of the system components. Compressor's maximum, minimum and average inlet-outlet temperatures were measured as $19.03-69.42^{\circ} \mathrm{C}, 13.84-47.58^{\circ} \mathrm{C}$, and $15.94-60.42^{\circ} \mathrm{C}$, respectively. Condenser maximum, minimum and average temperature values were measured as $43.05-31.74^{\circ} \mathrm{C}, 31.80-26.06^{\circ} \mathrm{C}$ and $37.98-29.85^{\circ} \mathrm{C}$; evaporator temperature values were measured as $-1.94-4.55^{\circ} \mathrm{C},-4.78-0.50^{\circ} \mathrm{C}$ and $-3.33-1.99^{\circ} \mathrm{C}$.

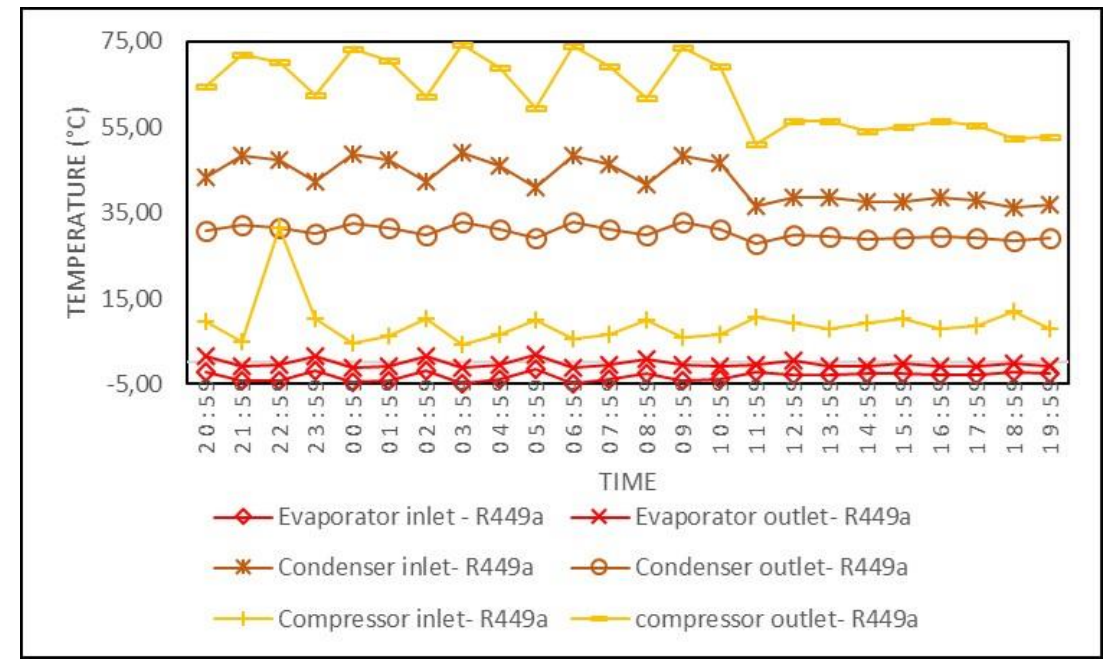

Figure 6. Temperature of the system components where R449A was used as refrigerant

Figure 7 shows the exergy destruction of the components in the system where R449A was used. Accordingly, the highest exergy destructions of the compressor, condenser, microchannel and evaporator are 0.7857 $\mathrm{W}, 0.2489 \mathrm{~W}, 0.6007 \mathrm{~W}$ and $0.1765 \mathrm{~W}$; minimum values are $0.6417 \mathrm{~W}, 0.1294 \mathrm{~W}, 0.4819$ and 0.0719 ; the average values are $0.7126 \mathrm{~W}, 0.1764 \mathrm{~W}, 0.4695 \mathrm{~W}$ and $0.21503 \mathrm{~W}$, respectively. Similarly, the exergy destruction of the compressor was the highest in the R449A refrigerant cooling system. With the improvement of the energyconsuming device compressor in the system or the reduction of energy consumption, the performance of the system will increase even more.

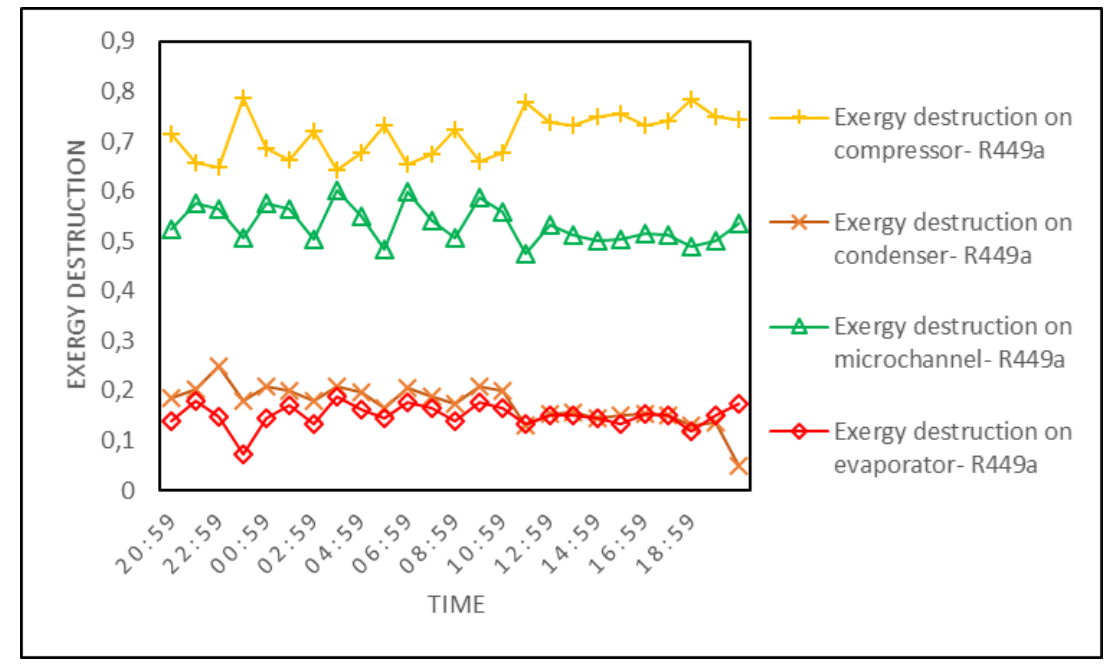

Figure 7. Exergy destruction of the system components where R449A was used as refrigerator

The comparative exergy efficiency of R290 and R449A refrigerants used in the experiments is given in Figure 8. Accordingly, in the experiments where R290 was used as refrigerant, maximum, minimum and average 
exergy efficiencies were calculated as $45.55 \%, 41.11 \%$ and $43.52 \%$, respectively. On the other hand, in the experiments where R449A was used as refrigerant, these values were determined as $27.12 \%, 17.81 \%$ and $22.28 \%$, respectively. Comparing average exergy efficiencies, it was observed that R290 produced $48.8 \%$ more useful energy than R449A.

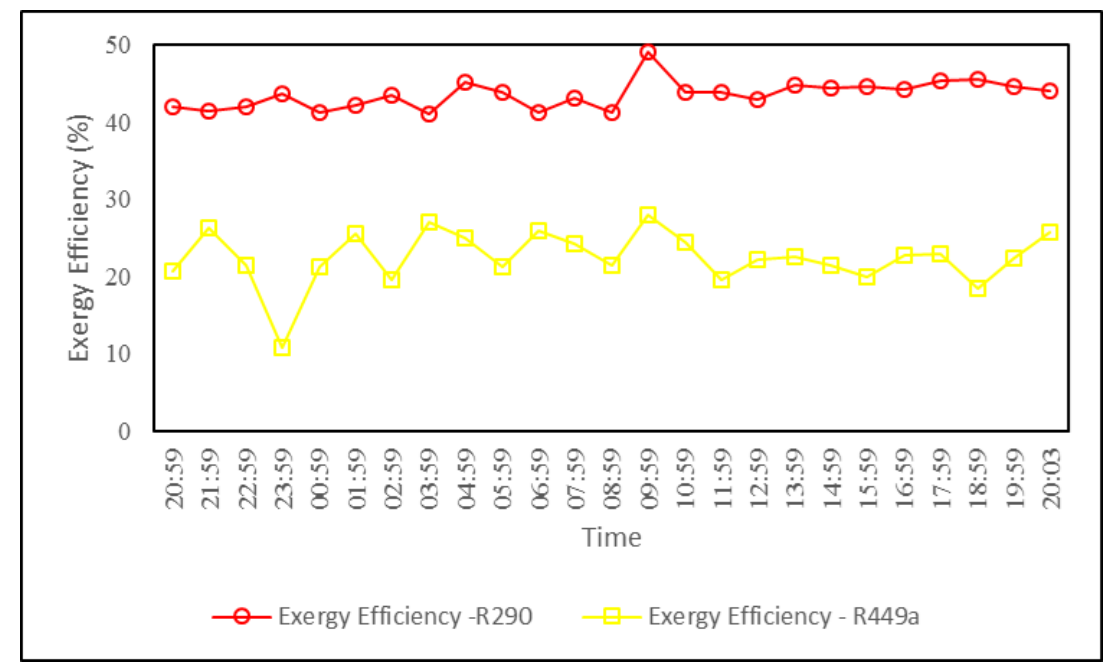

Figure 8. Exergy efficiency of the system

The comparative COP values of the system are given in the figure below (Figure 9). Accordingly, the maximum, minimum and average COP values obtained in the experiment using R290 refrigerant were determined as 2.36, 1.95 and 2.09, respectively, while these values were found to be 1.71, 1.53 and 1.59 for R449A refrigerant. It is known that in heat pump systems, when the heat transfer in the condenser is better or when the energy consumption in the compressor is decreased, the system increases the cooling performance. R290 refrigerant was calculated to be $23.92 \%$ more efficient compared to R449A.

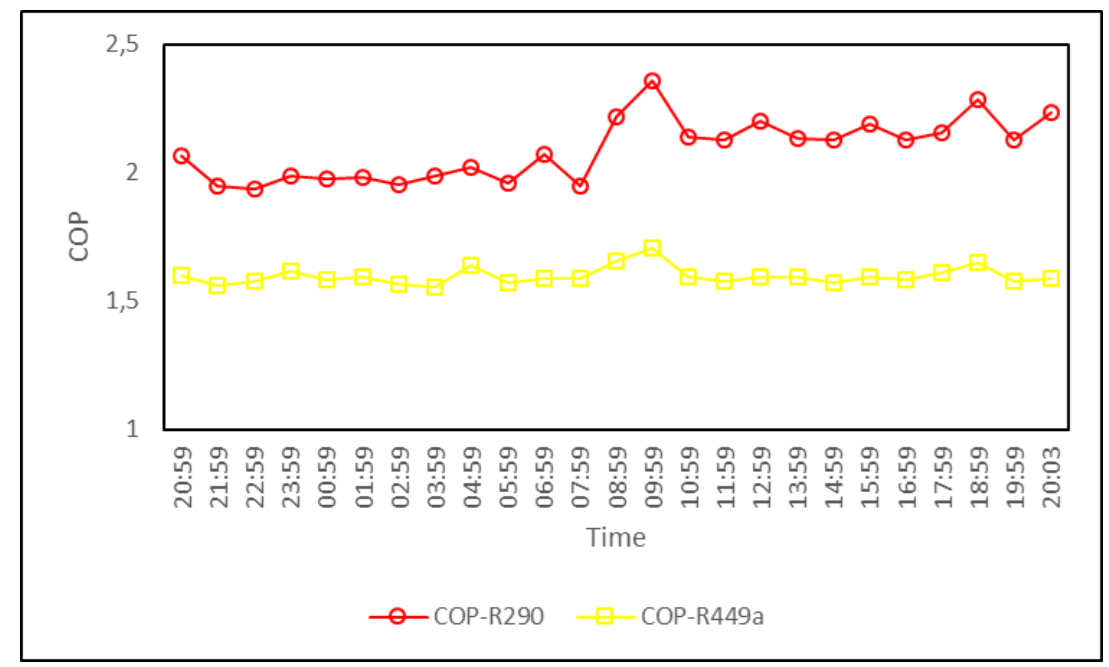

Figure 9. COP value of the system

Figure 10 shows the power $(\mathrm{kW})$ used by the compressor as a result of the use of refrigerant. Accordingly, while the power consumed by the compressor was $1.51 \mathrm{~kW}$ as a result of the use of R290, and $1.70 \mathrm{~kW}$ of power, as a result of the use of R449A. The high power consumed by the compressor in the R449A refrigerant system also 
negatively affected the COP, exergy efficiency, and exergy destruction. As a result, was been observed that R290 was a more efficient refrigerant than R449A.

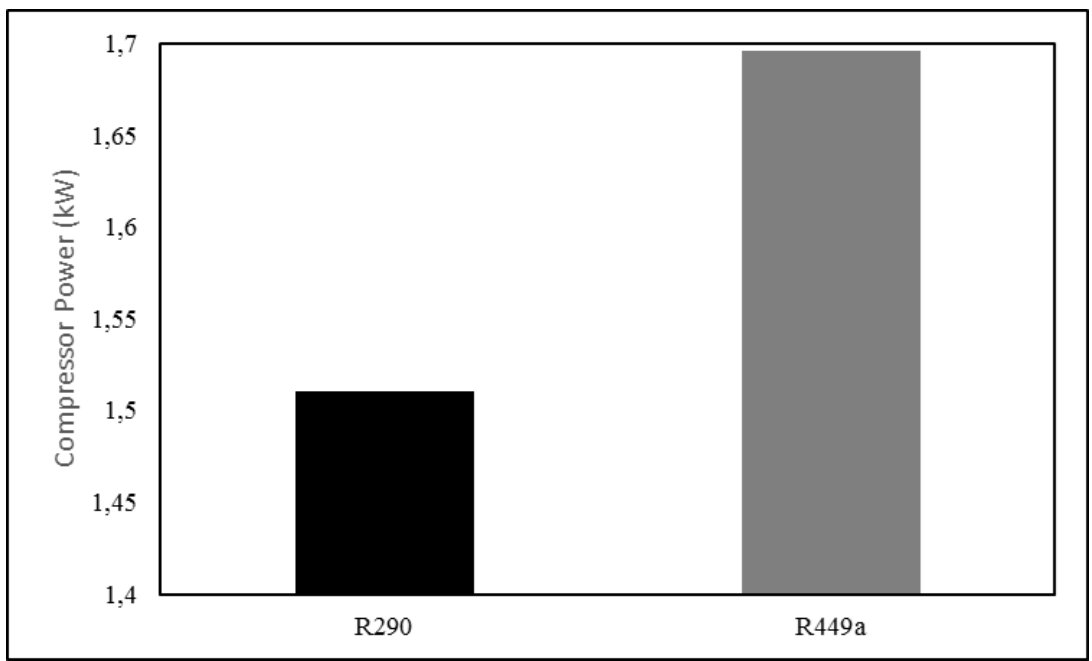

Figure 10. Comparison of the Compressor power $(\mathrm{kW})$ value of R290 and R449A refrigerants

It is seen that the power drawn from the compressor is different as a result of the use of two different refrigerants used in the system. Accordingly, the difference in the amount of $\mathrm{CO}_{2}$ emitted to the environment is

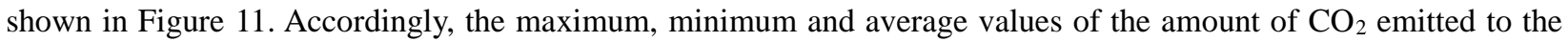
environment as a result of the use of R290 were calculated as 3.23, 2.96 and $3.14 \mathrm{~kg} / \mathrm{h}$. On the other hand, in the use of R449A, these values were calculated as 4.06, 3.85 and 3.97. As a result, $26.22 \%$ less $\mathrm{CO}_{2}$ was released to the environment as a result of the use of R290 compared to R449A.

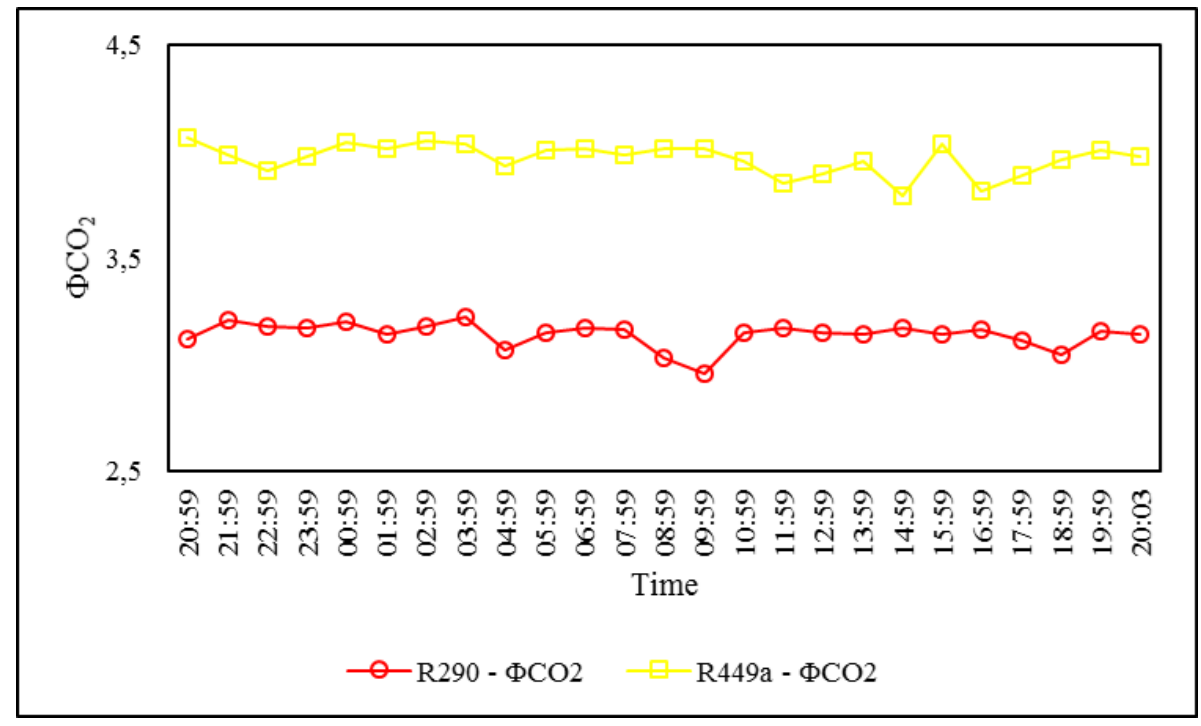

Figure 11. $\mathrm{CO}_{2}$ emission value of the system

In the experiment, package temperatures of 48 products, which were located in different compartments of the industrial cooler, were measured with thermocouples. As a result of these measurements, the average temperature values of the products in the left, middle and right compartments were calculated as $3.05{ }^{\circ} \mathrm{C}, 2.778{ }^{\circ} \mathrm{C}$ and $2.44{ }^{\circ} \mathrm{C}$, respectively, by using R290 as refrigerant (Figure 12). 


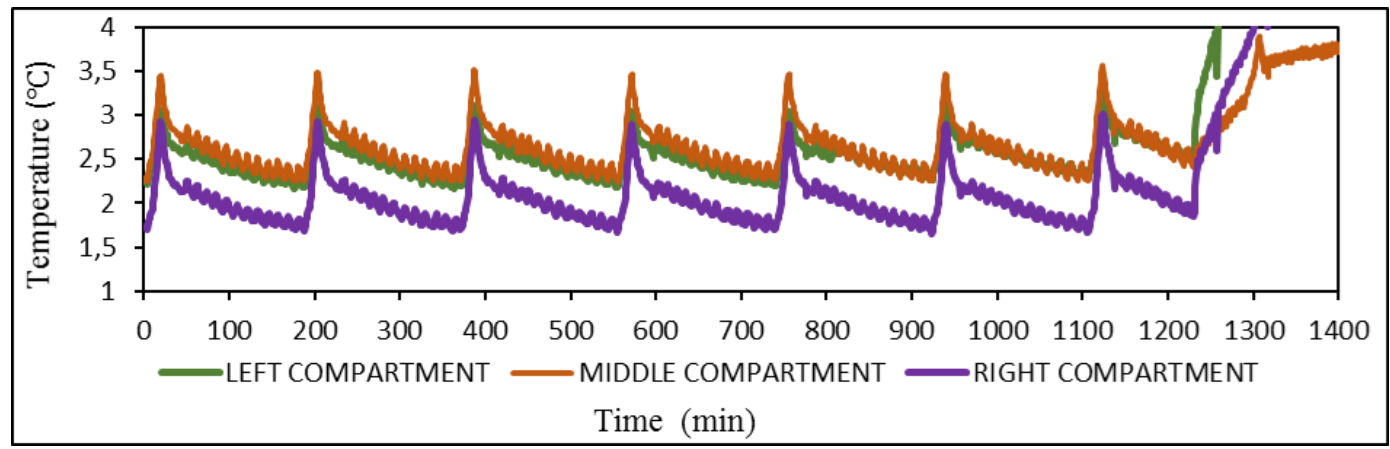

Figure 12. Package temperature for refrigerant R290

For R449A package temperatures of 48 products calculated as $3.76{ }^{\circ} \mathrm{C}, 3.25^{\circ} \mathrm{C}, 3.68{ }^{\circ} \mathrm{C}$. As can be seen in Figure 13, it is observed that the temperature values of the products in different compartments in the industrial cooler increase overtime during the defrosting process and then decrease again. This temperature change was measured as an average of $3.066^{\circ} \mathrm{C}$ on products.

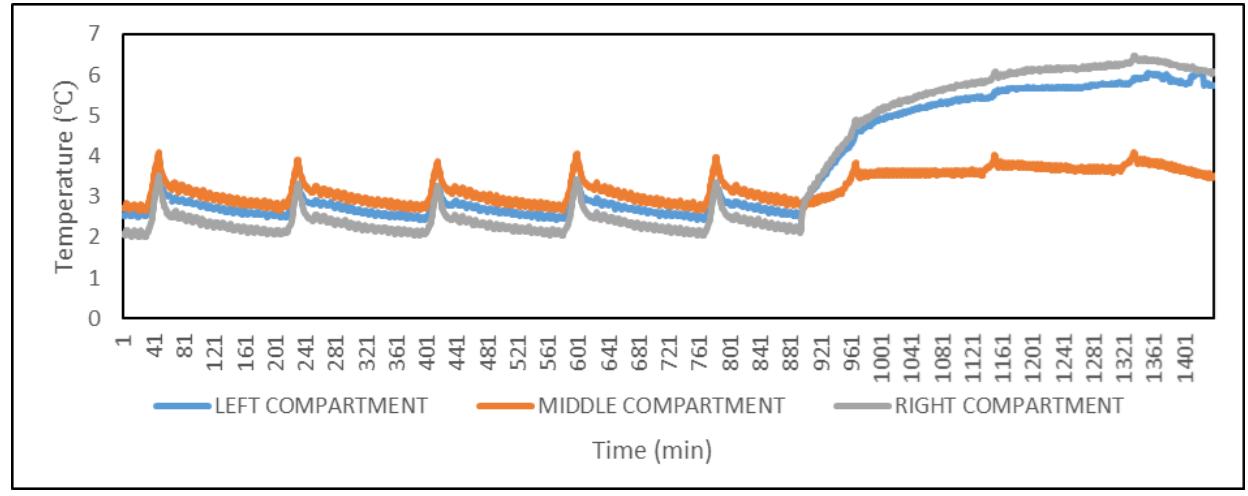

Figure 13. Package temperature for refrigerant R449A

When the two systems with R290 and R449a refrigerant are compared in terms of COP, exergy efficiency, and $\mathrm{CO}_{2}$ emission value, it is seen that the R290 refrigerant cooling system can provide a great advantage in terms of use in supermarkets. R290 refrigerant cooling system is both more performance and more environmentally friendly. The recommended cooling system with R290 refrigerant can be used reliably for many years in supermarkets.

\section{CONCLUSION}

In this paper, the refrigerants R290 and R449A were thermodynamically analysed for a system with double inlet and outlet evaporators and microchannel heat exchangers. Based on the measured compressor energy consumption, energy-exergy analysis and environmental impact assessment were made for each refrigerant type. It is possible to list the results as follows:

- By using R290 refrigerant, it has been handled 48.8\% more exergy efficiency.

- Using R290 higher 23.92\% COP value obtained.

- It was observed that R449A consumed $11.18 \%$ more compressor power than R290.

- $\quad \mathrm{R} 290$ emitted $26.22 \%$ less $\mathrm{CO}_{2}$ than R449A.

According to these conclusion, R290 refrigerant has a better achievement compared to R449A. Both refrigerants are recommended to cooling in supermarket, R290 refrigerant is a good alternative when the environmental effects are considered together. In cases where R290 is used as the working fluid, it is important to make designs that will increase the performance of cooling systems (use of ejectors and use of internal heat exchangers, etc.). 


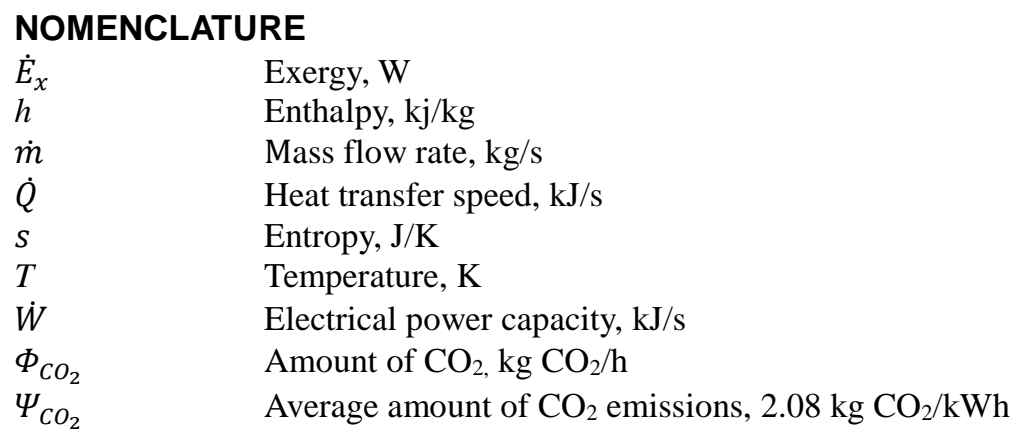

Greek symbols

Efficiency

Subscripts

$\begin{array}{ll}\text { comp } & \text { Compressor } \\ \text { con } & \text { Condenser } \\ \text { dest } & \text { Destruction } \\ \text { ex } & \text { Exergy } \\ \text { eva } & \text { Evaporator } \\ \text { mch } & \text { Microchannel }\end{array}$

\section{REFERENCES}

[1] Protocol M. Montreal protocol on substances that deplete the ozone layer. Washington, DC: US Government Printing Office, 1987;26:128-136.

[2] Low-Gwp A.O. Montreal Protocol On Substances That Deplete The Ozone Layer. 2019.

[3] Schulz M. and D Kourkoulas. Regulation (EU) No 517/2014 of The European Parliament and of the council of 16 April 2014 on fluorinated greenhouse gases and repealing Regulation (EC) No 842/2006. Off. J. Eur. Union, 2014. 2014;(517):L150.

[4] Ciconkov R. Refrigerants: There is still no vision for sustainable solutions. International Journal of Refrigeration 2018;86:441-448.

[5] Heredia-Aricapa Y. et al. Overview of low GWP mixtures for the replacement of HFC refrigerants: R134a, R404A and R410A. International Journal of Refrigeration 2020;111:113-123.

[6] He M.-G. et al. Application of natural refrigerant propane and propane/isobutane in large capacity chest freezer. Applied Thermal Engineering 2014;70(1):732-736.

[7] Makhnatch P. et al. Retrofit of lower GWP alternative R449A into an existing R404A indirect supermarket refrigeration system. International Journal of Refrigeration 2017;76: 184-192.

[8] Vaitkus L. and Dagilis V. Analysis of alternatives to high GWP refrigerants for eutectic refrigerating systems. International Journal of Refrigeration 2017;76:160-169.

[9] Razmi A. et al. Energy and exergy analysis of an environmentally-friendly hybrid absorption/recompression refrigeration system. Energy conversion and management 2018;164:59-69.

[10] Padalkar A.S. Mali K.V. and Devotta S. Simulated and experimental performance of split packaged air conditioner using refrigerant $\mathrm{HC}-290$ as a substitute for HCFC-22. Applied Thermal Engineering 2014;62(1):277-284.

[11] Yilmaz T. and Erdinç M.T. Energetic and exergetic investigation of a novel refrigeration system utilizing ejector integrated subcooling using different refrigerants. Energy 2019;168:712-727.

[12] Tang W. et al. The performance and risk assessment of R290 in a $13 \mathrm{~kW}$ air source heat pump. Applied Thermal Engineering 2018;144:392-402.

[13] Nasutio, D.M. M. Idris and Pambudi N.A. Room air conditioning performance using liquid-suction heat exchanger retrofitted with R290. Case Studies in Thermal Engineering 2019;13:100350.

[14] Wang X. and Yu J. Experimental investigation on two-phase driven ejector performance in a novel ejector enhanced refrigeration system. Energy Conversion and Management 2016;111:391-400.

[15] Liu X. Yu J. and Yan G. Theoretical investigation on an ejector-expansion refrigeration cycle using zeotropic mixture R290/R600a for applications in domestic refrigerator/freezers. Applied Thermal Engineering 2015;90:703-710. 
[16] Liu Y. et al. Compression-injection hybrid refrigeration cycles in household refrigerators. Applied thermal engineering 2010;30(16):2442-2447.

[17] Nawaz K. et al. R290 (propane) and R600a (isobutane) as natural refrigerants for residential heat pump water heaters. Applied Thermal Engineering 2017;127:870-883.

[18] Siang J.T. and Sharifian A. Performance of a single- duct portable propane air conditioning system under different refrigerant charge levels. Heat Transfer-Asian Research 2017;46(8):1246-1261.

[19] Chen Q. Yu J. and Yan G. Performance analysis of a modified zeotropic mixture (R290/R600) refrigeration cycle with internal subcooler for freezer applications. Applied Thermal Engineering 2016;108:172-180.

[20] Mohanraj M. et al. Experimental investigation of R290/R600a mixture as an alternative to R134a in a domestic refrigerator. International Journal of Thermal Sciences 2009;48(5):1036-1042.

[21] Chen Q. Yan G. and Yu J. Performance analysis of an ejector enhanced refrigeration cycle with R290/R600a for application in domestic refrigerator/freezers. Applied Thermal Engineering 2017;120:581-592.

[22] Tian Q. et al. An experimental investigation of refrigerant mixture R32/R290 as drop-in replacement for HFC410A in household air conditioners. International Journal of Refrigeration 2015; 57:216-228.

[23] Moallem E. et al. Effects of frost growth on louvered folded fins of microchannel heat exchangers on the time-dependent air side convective heat transfer coefficient. Experimental Thermal and Fluid Science 2017;88:326-335.

[24] Xu B. et al. Experimental investigation of frost and defrost performance of microchannel heat exchangers for heat pump systems. Applied energy 2013;103:180-188.

[25] Tosun M. et al. Integration of a mini-channel condenser into a household refrigerator with regard to accurate capillary tube length and refrigerant amount. International Journal of Refrigeration 2019;98:428-435.

[26] Cremaschi L. and Saad Yatim A. Oil retention in microchannel heat exchangers of an R134a refrigeration system and effects on their energy performance and system COP. Science and Technology for the Built Environment 2019;25(3):272-281.

[27] Bayrakçı H.C. and Özgür A.E. Energy and exergy analysis of vapor compression refrigeration system using pure hydrocarbon refrigerants. International Journal of Energy Research 2009;33(12):1070-1075.

[28] Aktaş M. et al. Designing a novel solar-assisted heat pump system with modification of a thermal energy storage unit. Proceedings of the Institution of Mechanical Engineers, Part A: Journal of Power and Energy 2019;233(5):588-603.

[29] Koşa M., et al. Performance analyses of sustainable PV/T assisted heat pump drying system. Solar Energy 2020;199:657-672.

[30] Caliskan H. Dincer I. and Hepbasli A. Exergoeconomic, enviroeconomic and sustainability analyses of a novel air cooler. Energy and Buildings 2012;55:747-756.

[31] Sovacool B.K. Valuing the greenhouse gas emissions from nuclear power: A critical survey. Energy Policy 2008;36(8):2950-2963.

[32] Tripathi R. Tiwari G. and Dwivedi V. Overall energy, exergy and carbon credit analysis of N partially covered photovoltaic thermal (PVT) concentrating collector connected in series. Solar Energy 2016;136:260267. 